\title{
De la pseudoterapia a la psicoterapia basada en evidencia ¿por qué es importante diferenciarlas?
}

\author{
From pseudotherapy to evidence-based psychotherapy, why is it important to differenciate \\ them?
}

\section{Jared Ramos García ${ }^{a}$, María L. Escamilla Gutiérrez ${ }^{b}$}

\begin{abstract}
:
The aim of this essay is to explain the difference between pseudotherapy and evidence-based psychotherapy, as well as the importance that the professional who wants to work in this field should be trained in evidence-based psychotherapy. In addition, it sets out those essentials tools that therapist needs to have in order to provide quality care.
\end{abstract}

Keywords:

Pseudotherapy, evidence-based psychotherapy, science, treatment.

\section{Resumen:}

El objetivo del presente ensayo es explicar el contraste existente entre las pseudoterapias y la psicoterapia basada en evidencia científica, así como la importancia que tiene que el profesional que quiera dedicarse a este rubro se forme en esta última. Además, se exponen aquellas herramientas esenciales con las que debe contar a fin de brindar una atención de calidad.

\section{Palabras Clave:}

Pseudoterapia, psicoterapia basada en evidencia, ciencia, tratamiento

\section{Introducción}

En el Monasterio de Santo Domingo de Silos aparece la insignia "una fe que vence a la duda", esta hace referencia a una necesidad de la humanidad allá en los siglos XI y XII de ejercer fe, o, en otras palabras, de creer en la verdad de algo, aunque se carezca de pruebas. La fe incluso superaba a la razón en aquellos tiempos. Sin embargo, hoy vivimos en el siglo XXI y la ciencia con sus grandes aportes deben sus resultados a la razón y no a la fe. Si bien es cierto que la fe es indispensable en las religiones o en lo espiritual, en la ciencia esta no tiene cabida. ${ }^{1}$

Se inicia con esta reflexión, ya que, en estos tiempos, hablando específicamente del campo de la psicoterapia, existen variedad de modelos psicoterapéuticos para atender la salud mental de millones de personas alrededor del mundo, no obstante, muy pocos de estos realmente tienen fundamento científico y por tal, sus resultados se reducen a una cuestión de fe.

a Autor de Correspondencia, Universidad Autónoma del Estado de Hidalgo, https://orcid.org/0000-0001-7142-7261, Email: ramos130895@hotmail.com

b Universidad Autónoma del Estado de Hidalgo, https://orcid.org/0000-0002-6318-4519, Email: maría_escamilla@uaeh.edu.mx 
Aquellos que practican estos modelos pseudoterapéuticos predican el argumento de que todo método es válido y sirve para el mismo fin, pero olvidan un hecho importante, de que hoy, a diferencia de siglos pasados, se cuenta con un método científico que nos permite conocer qué técnicas o teorías son funcionales en el tratamiento de la psicopatología. Esta idea es fundamental, pues teniendo en cuenta esto es más fácil delimitar qué es lo que necesita entonces un profesional en psicoterapia en su formación para responder a las demandas de la salud mental de la sociedad.

\section{Desarrollo}

Entonces ¿con qué herramientas debe disponer el profesional que quiera dedicarse a la psicoterapia? En primer lugar, es necesario que el terapeuta cuente con las habilidades necesarias en el campo de la entrevista psicológica, de tal manera que al integrar la información consiga llevar a cabo un análisis funcional de la conducta, en el que logre conocer con exactitud y de forma completa los síntomas que aquejan al cliente, en el entendido que dicha sintomatología puede presentarse en respuestas específicas a nivel motor, cognitivo y fisiológico ${ }^{2}$ por esto, las preguntas han de ser orientadas a estos aspectos, así como al conocimiento de sus conductas protectoras, todo esto con el objetivo de estructurar un tratamiento ideográfico, a la medida. Sin embargo, el terapeuta tiene que evitar dar una impresión diagnóstica en la primera sesión porque la terapia implica un proceso de conocimiento amplio sobre las situaciones de un usuario para entender la raíz de su o sus problemas, por lo cual, una sesión resulta insuficiente para clasificar a una persona, además de que es una limitante que impide ver más características que pudieran ser útiles. ${ }^{3}$

Durante este proceso de evaluación y diagnóstico, a veces se precisa el empleo de pruebas psicométricas como apoyo para resolver ciertas dudas del sujeto en general, para ello es imprescindible que el profesional haga uso de instrumentos estandarizados para la población en que se vayan a ocupar y que estos sean válidos y confiables, en vista de que esto asegurará un aporte de información objetiva que permita un diagnóstico más preciso ${ }^{2}$. No obstante, es importante mencionar que basar un diagnóstico únicamente por los resultados obtenidos en una prueba sería un error, puesto que, como se mencionó al principio, los instrumentos son solo un apoyo al diagnóstico, se han de tener en cuenta los demás factores, tanto lo observado durante las sesiones de entrevista como en los instrumentos aplicados, revisar la literatura concerniente a la variables del problema, efectuar un análisis y entonces sí determinar el diagnóstico.

Ahora bien, esto no quiere decir que por hacer uso de un método riguroso, el terapeuta tenga que serlo en su trato, gran parte de la eficacia de cualquier tratamiento psicoterapéutico se logra por medio de establecer una relación entre Profesional-Cliente dado por un clima empático de escucha activa; es como mirar la ventana del otro ${ }^{3}$, es decir, tratar de ver su mundo como ellos lo perciben, para así realmente entender qué es lo que necesita cada paciente, a su vez el paciente se sentirá en un clima de aceptación, en el que perciba que sus problemas son muy humanos y que nadie le va a juzgar por ello, lo cual facilita el proceso de ayuda y potenciación de las capacidades del usuario.

No hay que olvidar que se trata con seres humanos, con emociones, que buscan desesperadamente una salida a sus problemas, tienen la expectativa de encontrar la salida por medio del psicoterapeuta a las adversidades que presentan, de modo tal que le conceden un poder que ha de utilizar de la mejor manera, dado que estos pacientes hablan con los profesionales de cosas que jamás han podido hablar con alguien de su entorno y ese escape lo ven en el psicoterapeuta, dicha relación dinámica es necesaria para una práctica efectiva que permite que el cliente se sienta motivado a colaborar junto con el terapeuta. ${ }^{4}$

Esto último resulta importante debido a que el cliente no ha de ser visto como un receptor pasivo sino más bien como alguien activo. El buen terapeuta es aquel que no hace dependiente al usuario, a razón de que el 
objetivo último es que desarrolle la capacidad de aprender a utilizar de forma independiente las herramientas que el profesional le brinde. El terapeuta por tal razón, evitará mostrarse como el solucionador absoluto de los problemas del cliente, indicándole todo el tiempo lo que tiene que hacer, algo que, sin duda, entorpecería la capacidad del usuario de tomar el curso de su vida, más bien lo que se pretende es que el usuario perciba al profesional como un orientador, usando, por ejemplo, el dialogo socrático se logra un tipo de autocuestionamiento colaborativo, que se opone a la instrucción didáctica unilateral, y más bien, apoya la autonomía, la autoeficacia y la autoconfianza del cliente. ${ }^{4}$

La terapia es como enseñarle al paciente a volar, pero enseñar a volar implica también enseñar a caer, es preciso prevenir que el usuario una vez que ha adquirido estas herramientas desarrolle un miedo irracional a recaer, para ello, es necesario mostrarle que es normal y parte del proceso el errar y que no por ello la vida termina, en pocas palabras, el propósito es que él pueda aceptar tanto los aciertos como los puntos negativos de la vida y los emplee como una oportunidad de crecimiento. ${ }^{5}$

Ahora bien, ya que se han integrado estos puntos, y se ha comenzado a planear el tratamiento, los métodos que decida utilizar el terapeuta durante el proceso tienen que estar basados en evidencia, todas aquellas propuestas que integren el influjo de energías invisibles o metafísicas que afectan el comportamiento del ser humano han de desecharse. Los planteamientos científicos deben ser verificables, es decir que, si un tratamiento ha sido probado empíricamente para determinado trastorno, entonces cualquier psicólogo que basa su trabajo en evidencia científica, debería ser capaz de aplicarlo y tendría que funcionar ${ }^{1}$. Por ello es importante que el profesional tenga conocimientos de metodología e integre un corpus de conocimiento en cuanto a técnicas y modelos que previamente hayan demostrado su eficacia como tratamiento. Claro, hay que tener presente que no todos las técnicas pueden ser utilizadas en diferentes personas con un mismo problema, puesto que a pesar de la similitud de necesidades, las capacidades físicas, cognitivas o conductuales del usuario llegan a ser diferentes, no es lo mismo, por ejemplo, emplear una técnica de autorregistro con una persona joven de estudios medianos con problemas de ansiedad a una persona con el mismo problema, pero de la tercera edad y con un bajo nivel de estudios, por ello es importante que se haga una muy buena observación de las características del cliente.

A su vez, ya que se ha integrado un tratamiento concreto es necesaria la evaluación continua de este durante el proceso de tal manera que, si un tratamiento no está dando resultados, pueda modificarse inmediatamente. Hablando de esto, existe cierta discrepancia en el modo en que puede brindarse la ayuda al cliente, debido a que, por un lado se tiene la opción de, únicamente atacar la queja específica del usuario o proporcionarle las herramientas necesarias no solo para solucionar el problema sino diversos problemas que pudieran surgirle, ambas opciones son válidas, no obstante, se considera que es más significativo pensar en el desarrollo completo del individuo, al impulsar todo su potencial cognitivo y conductual, si bien es cierto, es importante atacar desde el inicio el síntoma del cliente, considerando que de ese modo el usuario se sentirá impulsado a continuar con la terapia, una vez logrado esto, hay que impulsarlo a mejorar de forma global otros aspectos en los que se pueda desarrollar mejor.

Indudablemente el trabajo de aquel que quiera dedicarse a la psicoterapia requiere mucho trabajo, estudio y práctica, pero sobre todo amar este proceso, pues si no se ama algo no se puede dar el máximo porque no hay un componente lo suficientemente motivante para promover un cambio en el otro. Por ello, si el terapeuta descubre poco interés por este trabajo lo mejor sería que opte por dedicarse a otra cosa. Ahora bien, es primordial que el profesional procure su salud mental en todo momento y es que, trabajar tantas horas a la semana cargando con las emociones negativas de los demás podría ser muy desgastante, por autocuidado, se ha de tener en cuenta hasta qué punto llega su responsabilidad como prestador de servicios y cuando ya no, es decir, una 
vez fuera del consultorio el profesional ya no es responsable de la o las situaciones del usuario, en vista de que el cliente es el único responsable de su problema.

\section{Conclusión}

A través de este ensayo se ha resaltado la importancia de emplear una psicoterapia que se construya a base de aspectos metodológicos basados en evidencia científica, a razón de que hoy a diferencia de siglos pasados, se cuenta con los medios que permiten saber qué tratamientos, modelos o técnicas son las más adecuadas y eficaces para un determinado problema. Sería un desperdicio reducir el quehacer profesional a una cuestión de fe o de intuición teniendo todo lo necesario para dar una asistencia de calidad, confiable y válida. Formar parte de un método riguroso no significa convertirse en robot, por el contrario, se presentan sentimientos con el paciente, ambos son humanos y entrar en contacto con esa parte humana, ofrece la oportunidad de hacer más eficaces los tratamientos.

Lamentablemente como se mencionó al principio hoy existen diversas formas de hacer psicoterapia, pero muy pocas han sometido sus métodos a un análisis riguroso de carácter científico que permita saber si realmente es funcional para tratar determinada problemática, por lo tanto, su validez se determina por la fe, por la intuición. Aquellos que se han entrenado a ese tipo de pseudoterapias afirman que funcionan sus tratamientos, pero este aparente funcionamiento se debe más bien al resultado de lo que se conoce como efecto placebo ${ }^{1}$, es decir, que es la propia expectativa del cliente, sus pensamientos de que se va a curar lo que genera esa sensación de bienestar a corto plazo y no los componentes del tratamiento. Esos pensamientos de autosugestión es lo que modifica los comportamientos y reacciones afectivas del usuario, pero no se puede asegurar que las causas deban su origen al tratamiento. A diferencia de estas, en un modelo basado en evidencia científica todo esto se somete a prueba precisamente para descartar que los efectos del tratamiento se expliquen por el afecto placebo o por otras variables ajenas.

Sin duda es un gran privilegio poder asistir a aquellos que por alguna razón les es imposible continuar su vida normal por lo que sea, o también, a aquellos que buscan potenciar su habilidades personales, sin embargo, se requiere una correcta formación y sensibilidad para poder realmente ayudar a quien lo requiera, lo cual en gran parte es lo que la experiencia junto con una continua formación teórica va aportando al terapeuta y sobre todo, lo que diferenciará al personal competente de aquellos que no lo son.

\section{REFERENCIAS}

[1] Caballo V, Salazar I. Ingenuos. El engaño de las terapias alternativas. Madrid, España: Siglo XXI; 2019.

[2] Caballo V. Manual de Técnicas de Terapia y Modificación de Conducta. Madrid, España: Siglo XXI; 1998.

[3] Yalom I D. El don de la terapia. 2da ed. España: Emecé; 2003.

[4] Okamoto A, Dobson K, Dattilio F, Kazantzis N. The therapeutic relationship in cognitive-behavioral therapy: essential features and common challenges. Practice Innovations. 2019; 4:112-123.

[5] Borja G. La locura lo cura: Un manifiesto terapéutico. 5ta ed. Barcelona: Ediciones la llave; 2011 